\title{
Nonlinear Analysis of Reinforced High Strength Concrete Deep Beams With Openings
}

\author{
Baraa Jabbar Mahmood - Assistant Lecturer
}

Civil Engineering Department - College of Engineering - University of Mosul - Iraq

\begin{abstract}
The objective of this study is to estimate the influence of web openings in reinforced concrete deep beams by using nonlinear finite element analysis. Concrete represented by isoperimetric eight nodes, serendipity plane stress, elements. The reinforcement treated as embedded elements and considered as elastic perfectly plastic. New constitutive models to simulate concrete material suggested by means of a nonlinear regression analysis of many experimental data by using SPSS 16 - statistical program. Strain hardening approach was employed to model the compressive behavior of high strength concrete. In tension two models were used to model high strength concrete in the pre - peak and post peak states. A smeared fixed crack approach of cracked concrete in tension is assumed. Three variables included concrete strength, shear span to - depth ratio and the width and depth of openings. The results indicated that the ultimate strength is remarkably decreased in deep beams with openings rather than deep beams. Experimental results for reinforced high strength concrete deep beam with openings compared with the finite element results and showed good agreement.

Keywords: Deep beam, Finite element, High strength concrete, Nonlinear analysis, Openings, New constitutive models.

$$
\begin{aligned}
& \text { التحليل غير الخطي للعتبات الخرساتية المسلحة العميقة عالية المقاومة بوجود القتحات }
\end{aligned}
$$

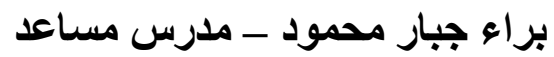

$$
\begin{aligned}
& \text { قسم الهندسة المدنية/ كلية الهندسة/ جامعة الموصل ملئل } \\
& \text { الخلاصة }
\end{aligned}
$$

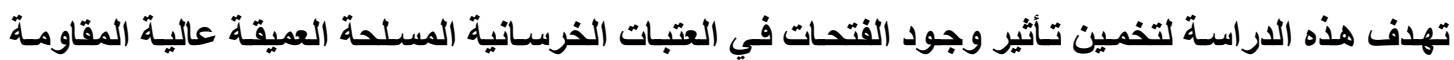

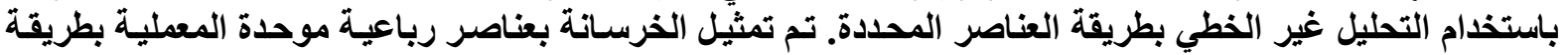

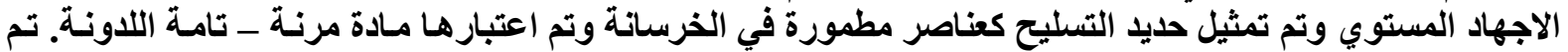

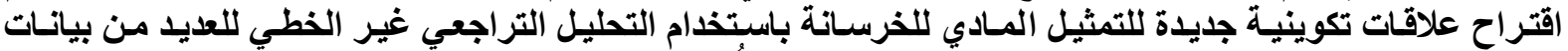

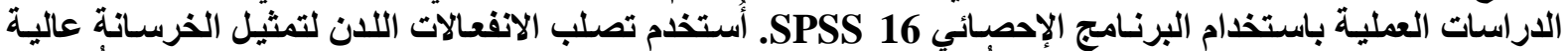

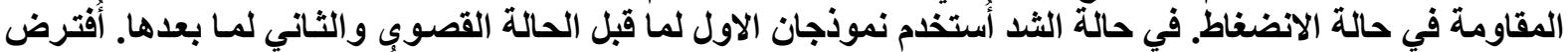

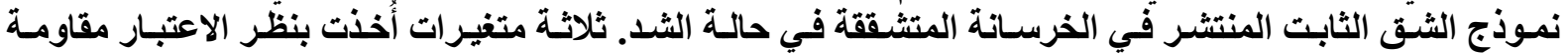

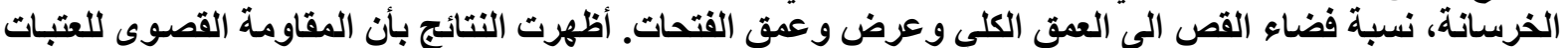

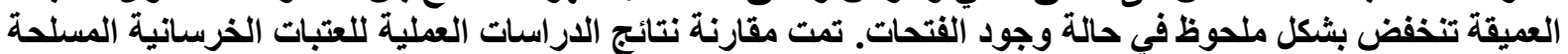

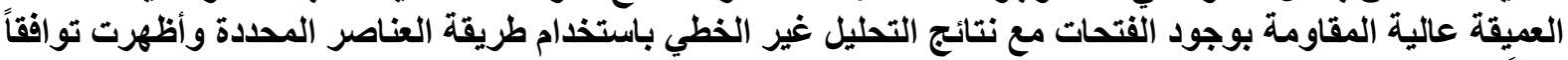




\section{Introduction}

Recently, the compressive strength of concrete is be coming higher. Concrete with compressive strength above $100 \mathrm{MPa}$ is available for structural applications [1].

By using High Strength Concrete (HSC), high and complex building can constructed, however, its is well known, when the concrete strength is increased, concrete becomes more brittle. HSC is very often used in modern complicated structures with large height and span, such as sky - spacer, high towers, and large span bridges, structures that are more vulnerable to damages caused by earthquake and wind [1]. HSC is increasingly used in these buildings because the use of HSC can reduced the dimensions of the structural members and hence save space [2].

Because the nature of fracture in HSC is brittle, therefore, the investigation behavior of flexure HSC members is important. When the concrete strength get higher, some of its characteristics and engineering properties, become different from those of normal strength concrete. These differences in material properties may have important consequences in term of structural behavior and design of HSC members [3].

Deep beams are structural elements loaded as beams but having small shear span - to - depth ratios. These have useful applications in many structures, such as tall buildings, foundations, offshore structures and several others and some shear walls are examples [4].

If the openings interrupt the load path joining the loading and reaction point, it is obvious that the simple load path changes to a more complex one, and the shear capacity will be reduced [5].

Yang et al., [4] tested twenty-one HSC deep beams, to investigate their shear characteristics with variables; concrete strength, shear span - to - depth ratio, and overall depth. They were concluded that the decrease in shear span - to - depth ratio, and the increase in overall depth led to more brittle failure, with wide diagonal cracks and high energy release rate related to size effects.

Yang et al., [5] were tested thirty - two reinforced high strength concrete beams with or without opening. Test variables included concrete strength, shear span - to - depth ratio and the width and depth of the opening. They were concluded that the influence of concrete strength on the ultimate strength decrease in deep beams with openings rather than solid beams.

Although HSC is being used in concrete deep beams with openings, there is no clear information regarding the effect of concrete strength on shear strength of deep beams with openings.

\section{Materials Constitutive Relationships}

\section{Compressive Stress - Strain Relationship}

Strain hardening approach was adopted in this study. The uniaxial stress-strain curve is assumed to be linear up to a stress level equals to $\mathbf{C}_{\mathbf{p}} \mathbf{f}^{\prime}{ }_{\mathbf{c}}$ followed by a parabolic shape up to peak compressive stress, where $\mathbf{C}_{\mathbf{p}}$, is the plasticity coefficient which is used to mark the initiation of the plastic deformation. For normal strength concrete a value of $\mathbf{0 . 3}$ is usually used and $\mathbf{0 . 5}$ for high strength concrete [6]. To determine the consecutive expansion of the loading surface during the plastic strain case it is necessary to employ the hardening rule, the relation between effective stress and effective plastic strain is extrapolated from the uniaxial stress-strain relationship.

From the experimental results of references [7, 8 and 9], a regression analysis used to derive the following uniaxial stress - strain relationship of HSC in Compression, as shown in Figure (1) (with index of determination $=99.7 \%$ ). 
$\mathbf{f}=\mathbf{f}_{\mathrm{c}}^{\prime}\left[\mathbf{A}\left(\frac{\varepsilon}{\varepsilon_{\mathrm{p}}}\right)-\mathbf{B}\left(\frac{\varepsilon}{\varepsilon_{\mathrm{p}}}\right)^{2}\right]$

where; $\mathbf{f}$ : Compressive stress corresponding to $\boldsymbol{\varepsilon}$ in (MPa).

$A=40.258 f_{c}^{\prime(-0.752)}, B=5151 f_{c}^{\prime(-2.148)}$

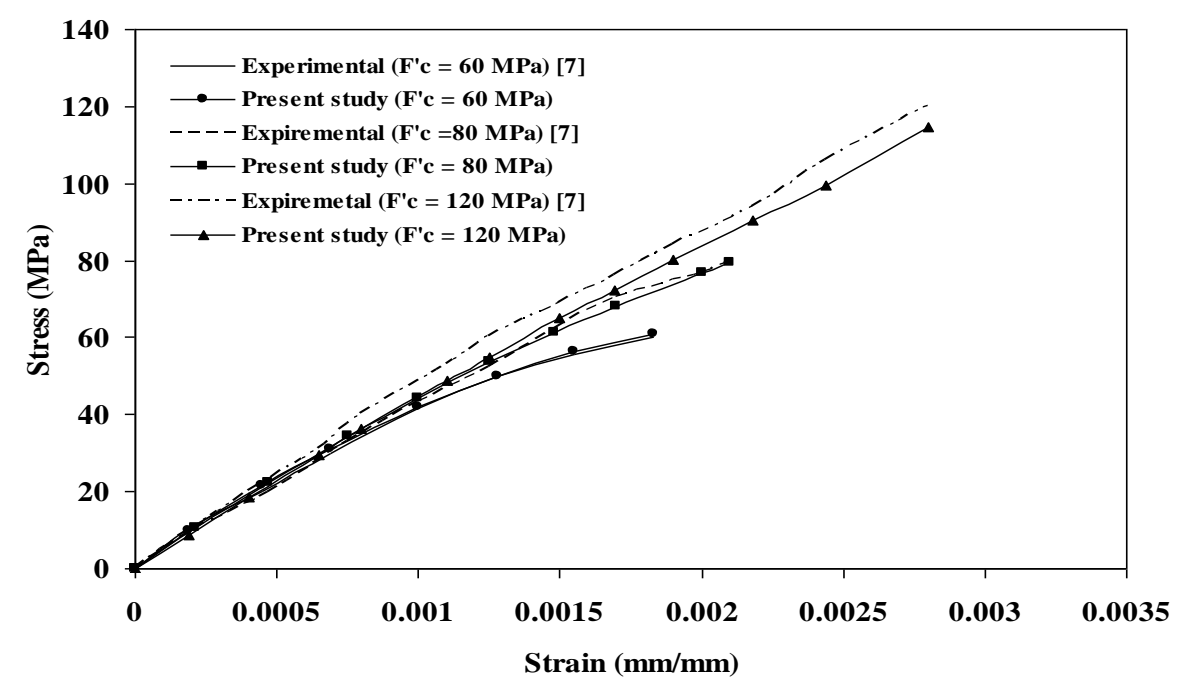

Figure (1): Uniaxial stress - strain relationship of HSC in compression

\section{Compressive Strain at Peak Stress}

A regression analysis for experimental results of references [7, 8 and 9] gives the following relationship between peak strain and compressive strength for HSC (with index of determination $=99.7 \%$ ), as shown in Figure (2).

$\varepsilon_{p}=0.000418 f_{c}^{\prime 0.396}$

where; $\boldsymbol{\varepsilon}_{\mathbf{p}}$ : Peak strain $(\mathrm{mm} / \mathrm{mm})$.

$\mathbf{f}^{\prime}{ }_{\mathbf{c}}$ : HSC Compressive strength, in (MPa).

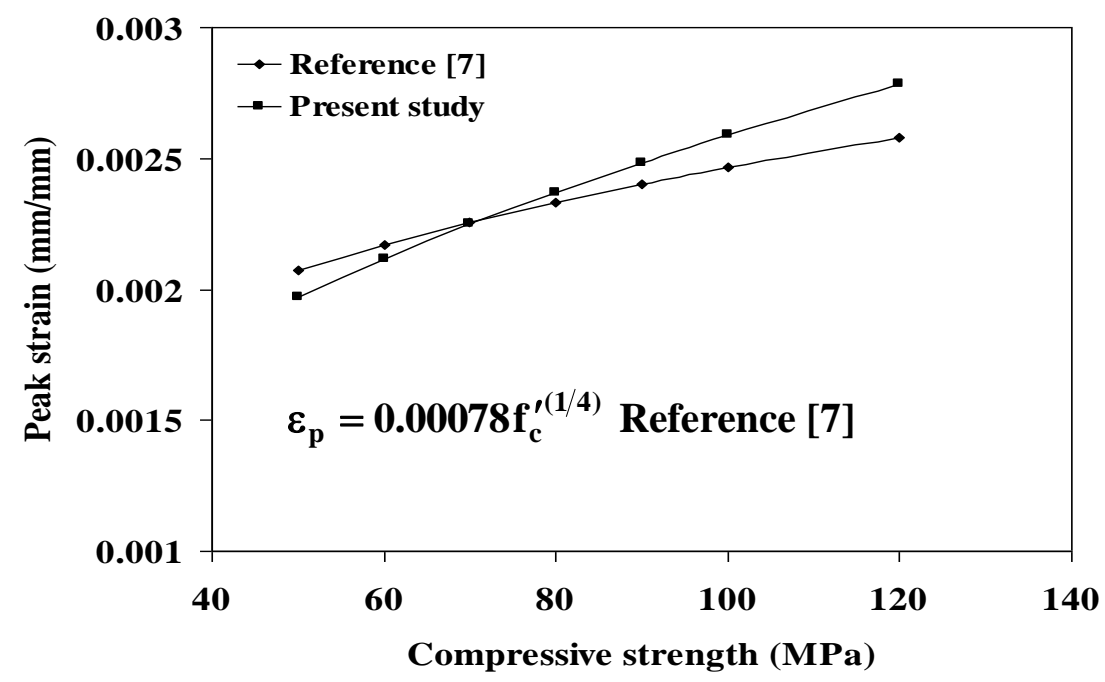

Figure (2): Peak strain as function of compressive strength 


\section{Modulus of Elasticity}

The equation was suggested by Wee et al., [7] is adopted in the present study to represent the initial tangent modulus of elasticity $\mathbf{E}_{\mathbf{i t}}$ as a function of concrete strength $\mathbf{f}_{\mathbf{c}}{ }_{\mathbf{c}}$ :

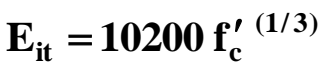

where; $\mathbf{E}_{\mathbf{i t}}$ : initial tangent modulus of elasticity of HSC in (MPa).

\section{Tensile Stress - Strain Relationship}

The tensile stress - strain relationship is represented by separating it into two regions, namely the pre - peak and post - peak region for HSC.

For pre - peak, by making a regression analysis of experimental results of references [9 and 10], the comparison between experimental and numerical model shown in Figure (3) (with index of determination of 99.96\%):

$f=f_{t}^{\prime}\left[1-\left(1-\frac{\varepsilon}{\varepsilon_{t}}\right)^{C}\right]$

where; f: Tensile stress corresponding to $\boldsymbol{\varepsilon}$ in $(\mathrm{MPa})$.

$\mathbf{f}_{\mathbf{t}}^{\prime}$ : Tensile strength corresponding to $\boldsymbol{\varepsilon}_{\mathbf{t}}$ in $(\mathrm{MPa})$.

$C=1.274 f_{t}^{\prime}-8.0458 f_{t}^{\prime}+14.527$

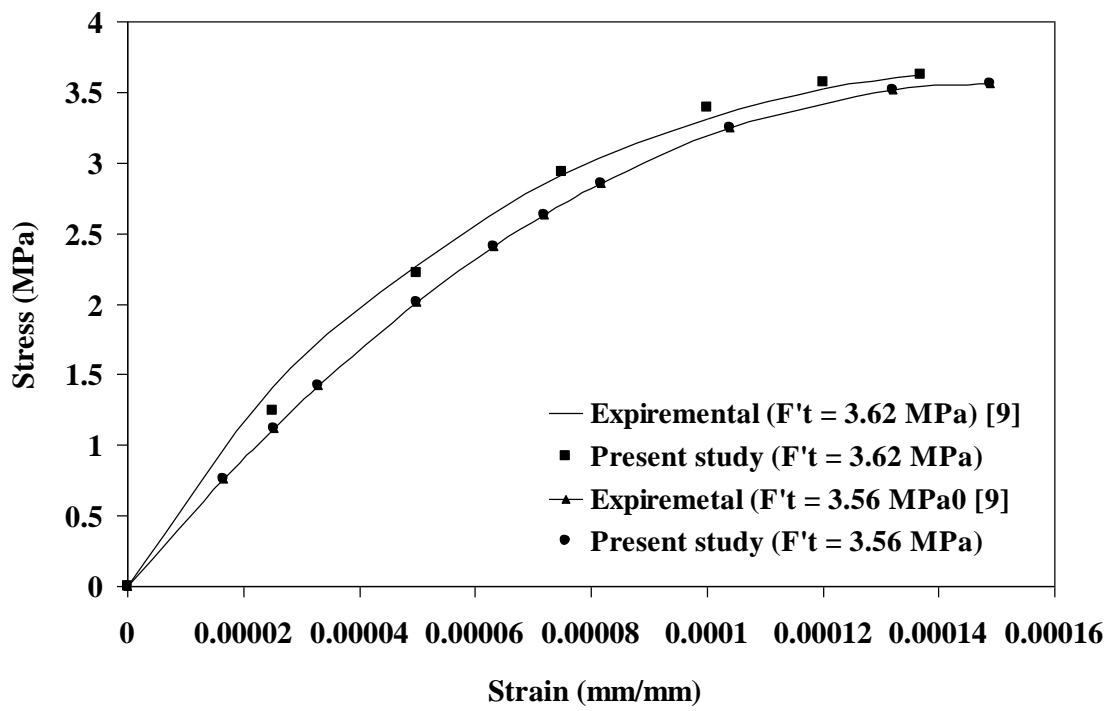

Figure (3): Uniaxial stress - strain relationship of HSC in tension at pre - peak region

For post - peak region, by making regression analysis of the experimental results of references [9 and 10], the comparison between the experimental and numerical model is shown in Figure (4) (with index of determination $=98.97 \%$ ):

$\mathbf{f}=\mathbf{f}_{\mathrm{t}}^{\prime} \mathrm{e}^{-\mathrm{D}\left(\frac{\varepsilon}{\varepsilon_{\mathrm{t}}}-\mathbf{1}\right)}$

where;

$D=-1.693 f_{t}^{\prime 2}+11.202 f_{t}^{\prime}-17.719$ 


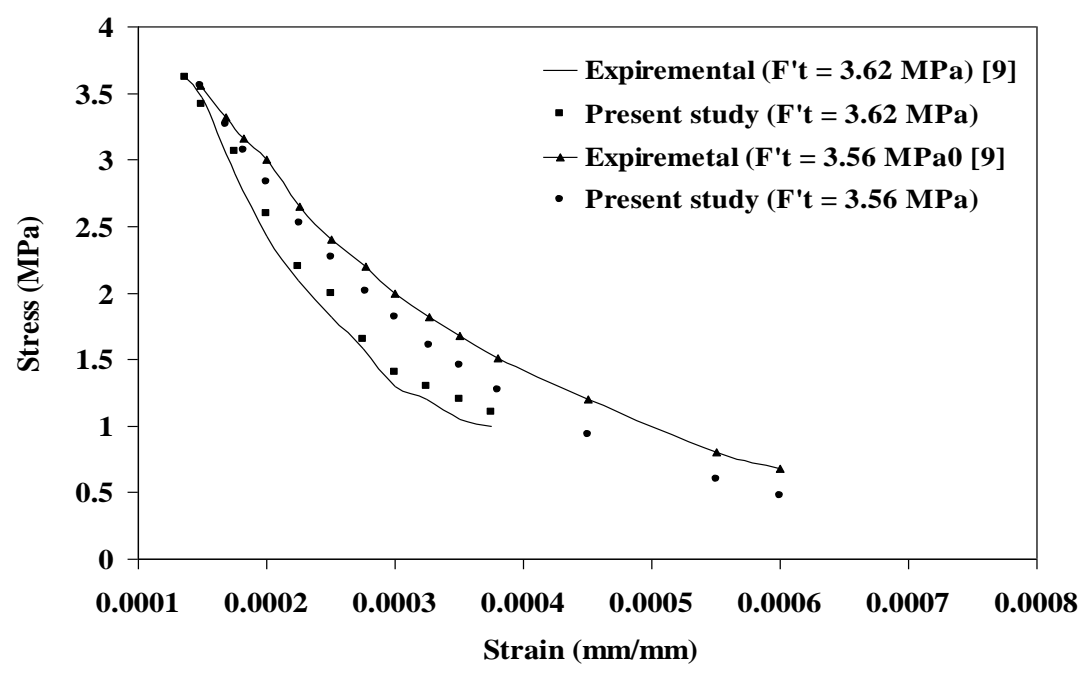

Figure (4): Uniaxial stress - strain relationship of HSC in tension at post - peak region

\section{Biaxial Behavior of HSC}

In compression - compression, A strain hardening plasticity approach is employed to model the compression behavior of concrete. A hardening role is chosen to describe the growth of yield surface during plastic loading.

A yield criterion was assumed to make initiation of plastic behavior [11]:

$\mathbf{f}\left(\mathbf{I}_{1}, \mathbf{J}_{2}\right)=\left[\beta\left(3 \mathbf{J}_{2}\right)+\alpha\left(\mathbf{I}_{1}\right)\right]^{0.5}=\mathbf{f}_{c}^{\prime}$

where, $\mathbf{I}_{\mathbf{1}}$ and $\mathbf{J}_{\mathbf{2}}$ are the first and second stress invariants and $\boldsymbol{\alpha}$ and $\boldsymbol{\beta}$ are material parameters:

$\alpha=\frac{1-\omega^{2}}{\omega^{2}-2 \omega}, \quad \beta=\frac{1-2 \omega}{\omega^{2}-2 \omega}$

where; $\omega$ : Stress ratio.

For biaxial compression test:

$\sigma_{1}=\sigma_{2}=\omega f_{c}^{\prime}$

For normal strength concrete $\boldsymbol{\omega}=\mathbf{1 . 1 6}$ [12], while, for HSC $\boldsymbol{\omega}=\mathbf{1 . 1 9 6}$, where the strength increase was $19.6 \%$ over that for uniaxial compression according to experimental results of reference [13] as shown in Figure (5).

In the tension - compression state, a regression analysis for experimental results of references [14, 15 , and 16], the shape of the strength envelope for biaxial tension compression of HSC is much more linear than that obtained for normal strength concrete, the comparison between

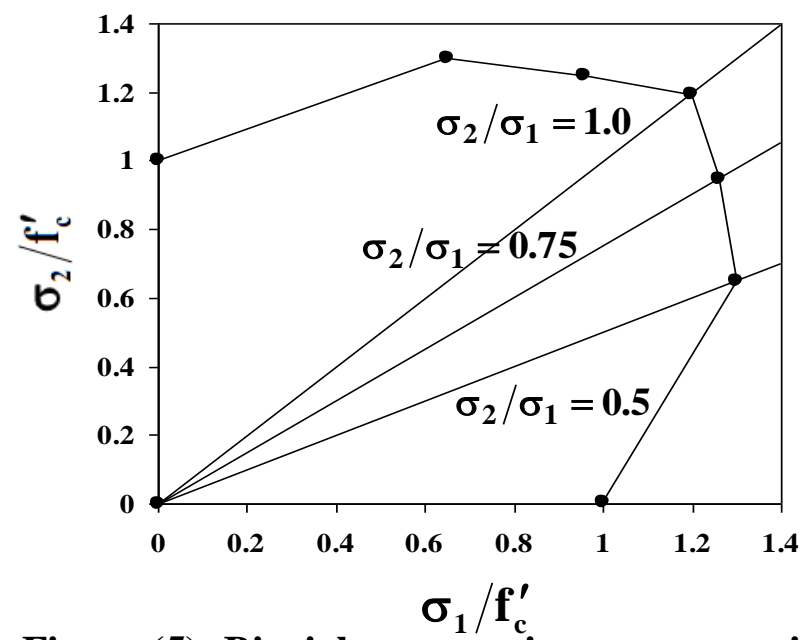

Figure (5): Biaxial compression - compression of HSC [13] 
experimental and numerical model shown in Figure (6) (with index of determination = 98.8\%):

$p\left(\frac{\sigma_{1}}{f_{c}^{\prime}}\right)+q\left(\frac{\sigma_{2}}{f_{c}^{\prime}}\right)=1.0$

where:

$$
\begin{aligned}
& p=1.847 \times 10^{-4} f_{c}^{\prime 3}-0.04 f_{c}^{\prime 2}+2.858 f_{c}^{\prime}-66.2 \\
& q=-0.00651 f_{c}^{\prime 3}+1.41 f_{c}^{\prime 2}-100.2 f_{c}^{\prime}+2362.5
\end{aligned}
$$

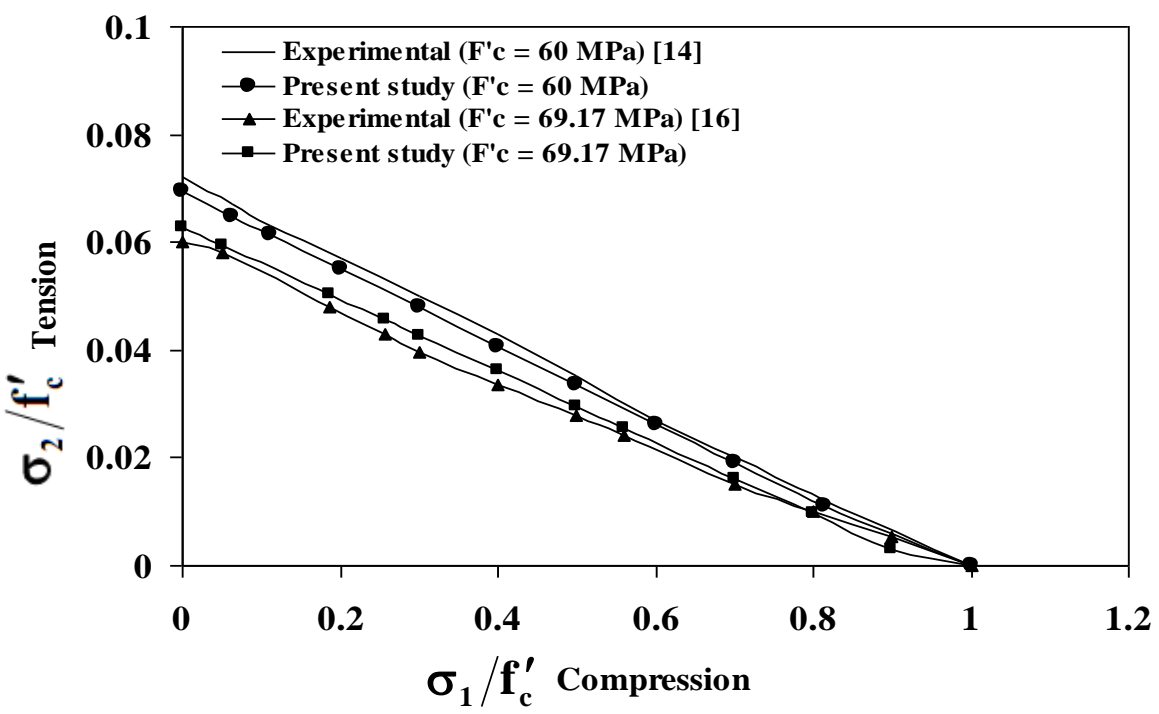

Figure (6): Biaxial compression - tension of HSC

\section{Tension - Stiffening}

After concrete is cracked the tensile stress decrease gradually because the pervasion of micro - cracks, due to bond effects, the cracked concrete of tensile force normal to cracked plane. The concrete hangs on the steel bar and contribute to the overall stiffness of the system. The stiffness effect, which is called tension stiffening. It can be accounted for in an indirect way by assuming a gradual loss of tension strength of the concrete. A post - peak part of the stress-strain curve, has represented this form. follows:

The secant modulus of elasticity for the post - peak region used in present study as

$$
\mathbf{E}_{\mathrm{i}}=\frac{\mathbf{f}_{\mathrm{t}}^{\prime} \mathrm{e}^{-\mathrm{D}\left(\frac{\varepsilon}{\varepsilon_{\mathrm{t}}}-1\right)}}{\varepsilon_{\mathrm{i}}} \quad \varepsilon_{\mathrm{i}}>\varepsilon_{\mathrm{t}}
$$

where: $\varepsilon_{\mathbf{i}}$ : the current tensile strain $(\mathrm{mm} / \mathrm{mm})$.

Also; the stresses $\sigma_{1}$ and $\sigma_{2}$ can be calculated by:

$$
\begin{aligned}
& \sigma_{1}=\mathbf{f}_{t}^{\prime} e^{-\mathrm{D}\left(\frac{\varepsilon}{\varepsilon_{\mathrm{t}}}-1\right)}, \quad \text { for } \varepsilon_{1}>\varepsilon_{\mathrm{t}} \\
& \text { or } \sigma_{1}=\sigma_{\mathrm{i}} \frac{\varepsilon_{1}}{\varepsilon_{\mathrm{i}}}, \quad \text { for } \varepsilon_{1}<\varepsilon_{\mathrm{i}}
\end{aligned}
$$

where; $\boldsymbol{\varepsilon}_{1}$ is strain in direction 1 . 


\section{Shear Modulus of Cracked Concrete}

Cervanka [17] proposed cracked shear modulus, which is used in this study:

$\overline{\mathbf{G}}=\mathbf{G}\left(1-\gamma^{\mathbf{k}}\right)$

where: $\mathbf{G}$ is the shear of uncracked concrete, $\overline{\mathbf{G}}$ is the cracked shear modulus, $\mathbf{k}=\mathbf{0 . 4}$, and $\boldsymbol{\gamma}$ is damage parameter

For concrete cracked in direction 1:

$\gamma=\varepsilon_{1} / 0.005$

For concrete cracked in direction 2:

$\gamma=\varepsilon_{2} / 0.005$

After cracking occurs in one direction, the concrete parallel to the crack direction is still capable of resisting tensile and compressive stresses. This was taken into account according to relationship proposed by Vecchio [18] :

$f_{\mathrm{cmax}}=\mu f_{\mathrm{c}}^{\prime}, \mu=\frac{1}{1+C_{\mathrm{s}} C_{\mathrm{d}}} \leq \mathbf{1 . 0}$

where; $C_{s}=0.55$, and $C_{d}=0.27\left(\frac{\varepsilon_{1}}{\varepsilon_{p}}-0.37\right)$

where; $\boldsymbol{\varepsilon}_{\mathbf{1}}$ is the tensile strain in direction normal to the crack, and $\boldsymbol{\varepsilon}_{\mathrm{p}}$ is compressive strain corresponding to $\mathbf{f}_{\mathbf{c}}^{\prime}$.

\section{Stress - Strain Relationship of the Steel Reinforcement}

Steel is homogeneous and has usually the same yield strength in tension and compression. A bilinear elastic perfect plastic model with strain hardening is used for steel bars as shown in Figure (7).

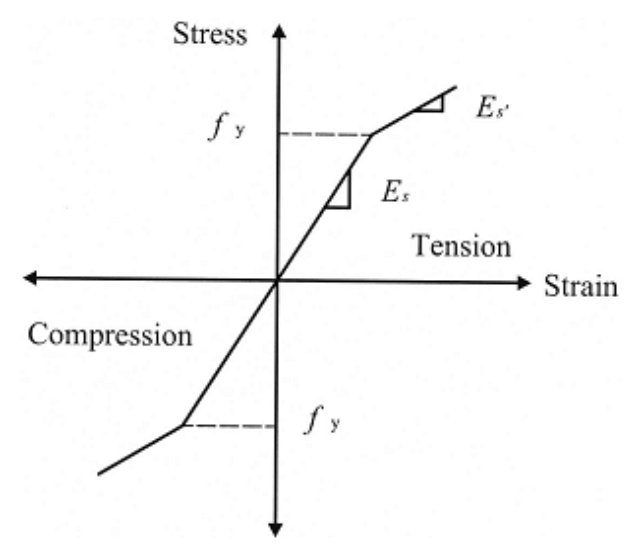

Figure (7): Stress - strain relationship for steel reinforcement

\section{Finite Element Formulation}

The eight-node serendipity plane stress elements are used in the present study. A $2 \times 2$ Gauss point integration rule (reduce rule) was given more accurate results than the full $\mathbf{3} \times \mathbf{3}$ integration. This formulation can be found elsewhere in references [19 and 20]. The smeared crack approach with fixed cracking model was used for crack representation. 
The embedded representation is used to simulate the reinforcement. The reinforcing bar is represented by an axial element embedded anywhere within the element. Perfect bond between reinforcement and concrete and its stiffness contribution can be evaluated by principles of superposition. The computer program used is that of reference [11] (where applied to fibrous concrete) with modification to be suitable for non - fibrous HSC.

In order to prevent the early local bearing failure due to stress concentration, the supports are simulated by applying a portion of the load at the two corners of the barriers plates in the reverse direction, in this study $\mathbf{0 . 1 5}$ of the applied load as used by reference [11] as shown in Figure (8):

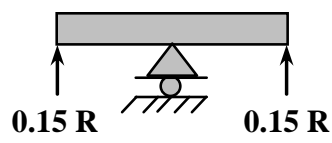

Figure (8): Support simulation [11]

\section{Numerical Applications}

A numerical example has been chosen in order to demonstrate the applicability of the program in the numerical analysis of HSC deep beams. The example presents the analysis of HSC deep beams with and without openings tested by Yang et al., [5].

All beams were $160 \mathrm{~mm}$ thick and $600 \mathrm{~mm}$ deep. The span length was constant at $2100 \mathbf{~ m m}$ depending on the shear span - to - depth ratio $(\mathbf{a} / \mathbf{h})$. Each beam has a main longitudinal reinforcement of $861 \mathrm{~mm}^{2}$ consisting of three $19 \mathbf{~ m m}$ diameter deformed bars. At the location of loading and support points, a $100 \mathbf{~ m m}$ wide steel plate was provided to prevent crushing or bearing failure as shown in Figure (9):

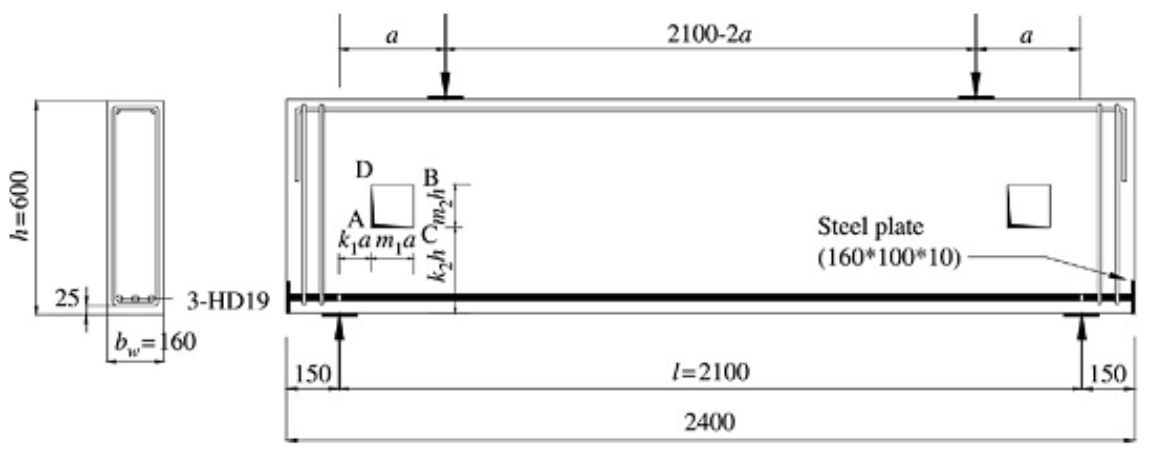

Figure (9): Typical specimen details [5]

Three variables of main interest for HSC deep beam are concrete strength, shear span to depth ratio, and the width and depth of the opening. The center of web opening of all beams was positioned at the center of shear span region. Table (1) shows the details of tested specimens considered in this study and Table (2) shows the longitudinal reinforcement properties. The identification of symbols utilized in this study is given in Figure (10).

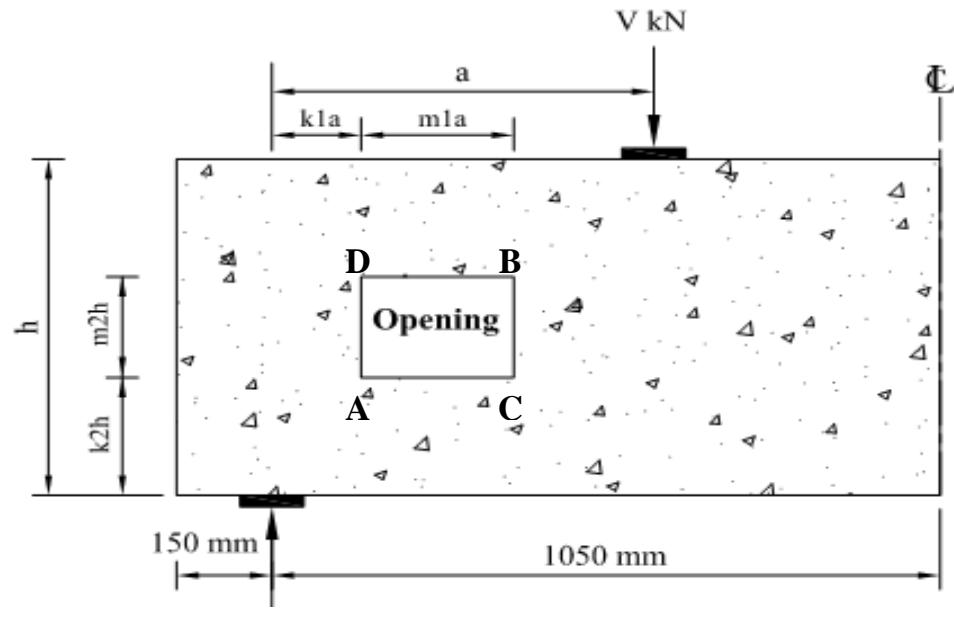

Figure (10): Identification of the svmbols 
Table (1): Details of test specimens [5]

\begin{tabular}{|c|c|c|c|c|c|c|}
\hline \multirow[t]{2}{*}{ Specimen } & \multirow{2}{*}{$\begin{array}{c}\text { Concrete } \\
\text { strength } \\
(\mathrm{MPa})\end{array}$} & \multirow[t]{2}{*}{$\mathbf{a} / \mathbf{h}$} & \multicolumn{2}{|c|}{$\begin{array}{c}\text { Size of opening } \\
(\mathbf{m m})\end{array}$} & \multicolumn{2}{|c|}{$\begin{array}{l}\text { Location of opening } \\
(\mathbf{m m})\end{array}$} \\
\hline & & & m1a & m2h & k1a & k2h \\
\hline L5NN & \multirow[t]{4}{*}{24} & \multirow{2}{*}{0.5} & 0 & 0 & 0 & 0 \\
\hline L5F3 & & & 150 & 180 & 75 & 210 \\
\hline L10NN & & \multirow[t]{2}{*}{1.0} & 0 & 0 & 0 & 0 \\
\hline L10F3 & & & 300 & 180 & 150 & 210 \\
\hline H5NN & \multirow[t]{4}{*}{50} & \multirow[t]{2}{*}{0.5} & 0 & 0 & 0 & 0 \\
\hline H5F3 & & & 150 & 180 & 75 & 210 \\
\hline H10NN & & \multirow[t]{2}{*}{1.0} & 0 & 0 & 0 & 0 \\
\hline H10F3 & & & 300 & 180 & 150 & 210 \\
\hline UH5NN & \multirow[t]{12}{*}{80} & \multirow[t]{6}{*}{0.5} & 0 & 0 & 0 & 0 \\
\hline UH5F1 & & & 150 & 60 & 75 & 270 \\
\hline UH5F2 & & & 150 & 120 & 75 & 240 \\
\hline UH5F3 & & & 150 & 180 & 75 & 210 \\
\hline UH5S3 & & & 195 & 180 & 52.5 & 210 \\
\hline UH5T3 & & & 75 & 180 & 112.5 & 210 \\
\hline UH10NN & & \multirow[t]{6}{*}{1.0} & 0 & 0 & 0 & 0 \\
\hline UH10F1 & & & 300 & 60 & 75 & 270 \\
\hline UH10F2 & & & 300 & 120 & 75 & 240 \\
\hline UH10F3 & & & 300 & 180 & 150 & 210 \\
\hline UH10S3 & & & 390 & 180 & 105 & 210 \\
\hline UH10T3 & & & 150 & 180 & 225 & 210 \\
\hline
\end{tabular}

Table (2): Longitudinal reinforcement properties

\begin{tabular}{|c|c|c|}
\hline Properties & With opening & Without opening \\
\hline Elastic modulus (MPa) & 200000 & 200000 \\
\hline Yield strength (MPa) & 420 & 820 \\
\hline $\mathbf{A}_{\mathbf{s}}\left(\mathbf{m m}^{\mathbf{2}}\right)$ & $3-19 \mathrm{~mm}$ & $3-19 \mathrm{~mm}$ \\
\hline
\end{tabular}

The specimens were divided into three series according to concrete strength that is $\mathbf{L}$ - series for $24 \mathrm{MPa}, \mathbf{H}$ - series for 50 MPa and UH series for $80 \mathrm{MPa}$.

Due to symmetry, one half of the deep beam has to be idealized in order to used the finite element idealization depending on the case study as shown in Figure (11):

Figures (12 to 19) show that the present study gives a good response as compared with the experimental load -

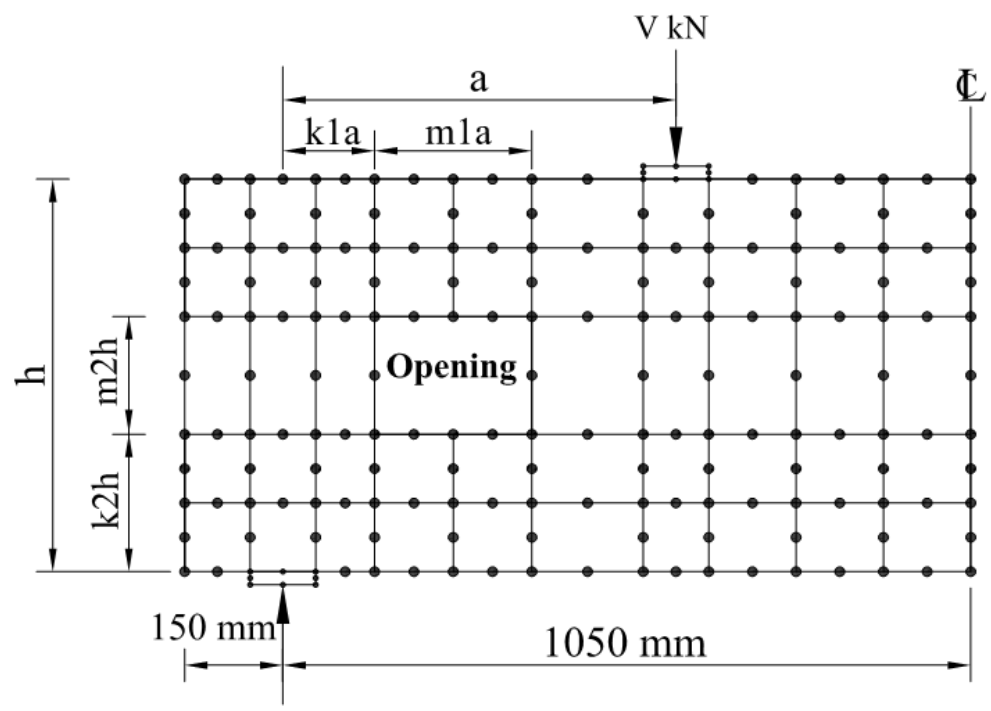

Figure (11): Finite element mesh layout 
deflection curves for different concrete strength (normal strength $\mathrm{L}$ - series and High strength $\mathrm{H}$ and $\mathrm{UH}$ - series), with and without openings (as shown in Table (1)), where, the shear span - to - depth ratio $(\mathrm{a} / \mathrm{h})$ is $\mathbf{0 . 5}$ and $\mathbf{1 . 0}$.

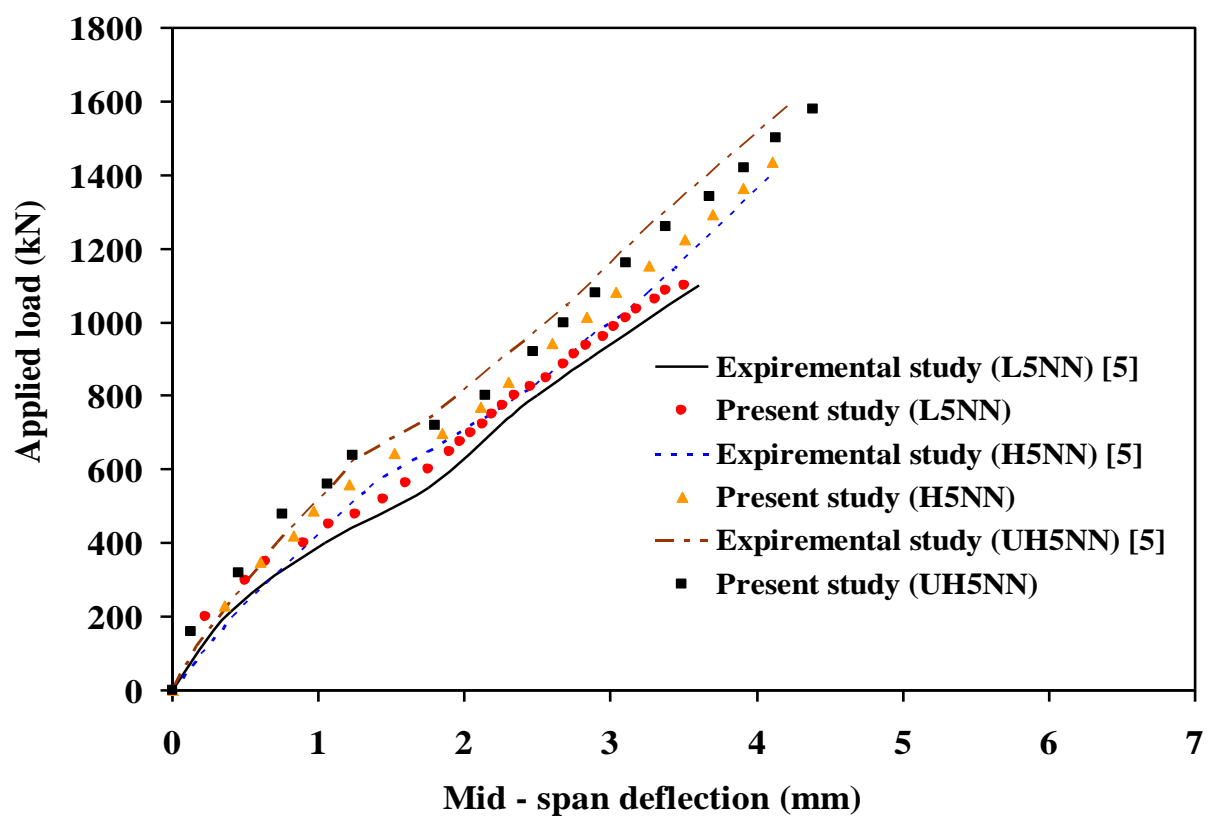

Figure (12): Load - deflection curve for (L5NN, H5NN and UH5NN) $(\mathrm{a} / \mathrm{h}=\mathbf{0 . 5})$

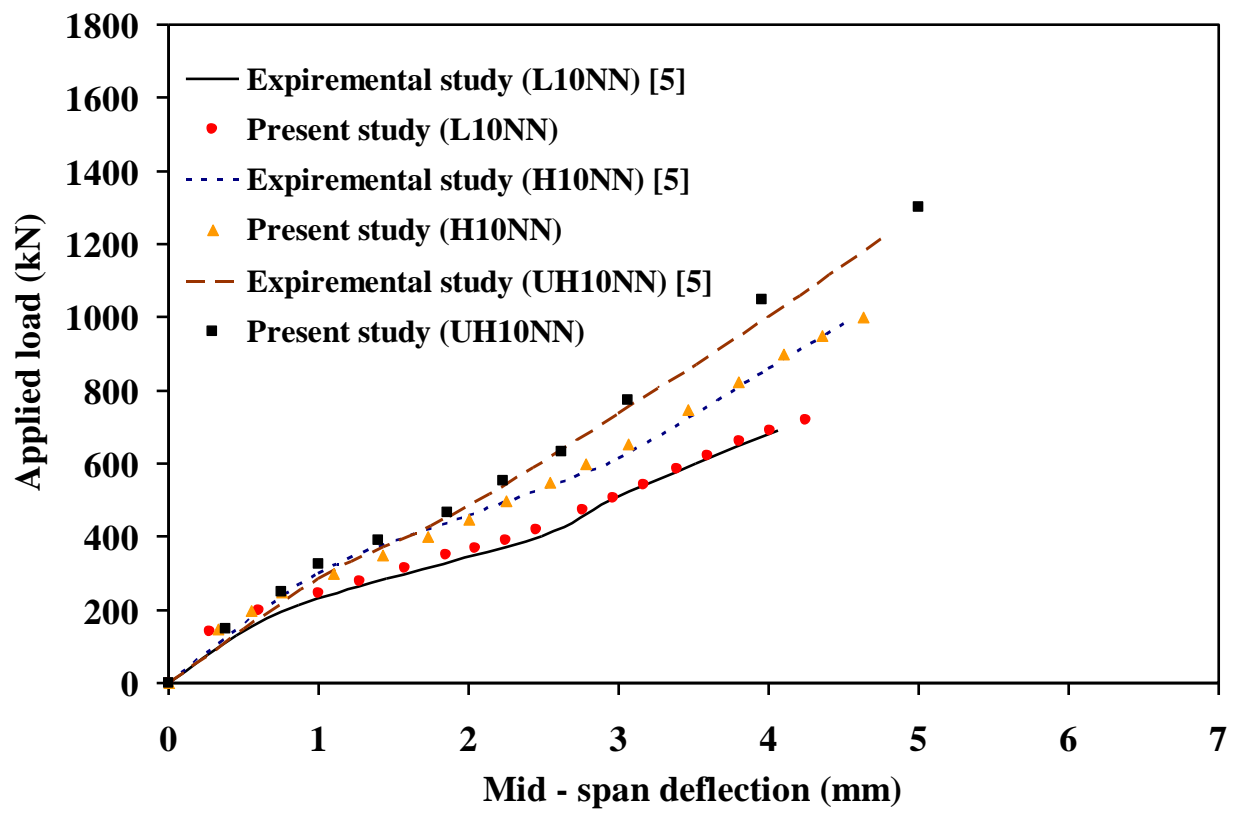

Figure (13): Load - deflection curve for $(\mathrm{L10NN}$, H10NN and UH10NN $)(\mathbf{a} / \mathrm{h}=\mathbf{1 . 0})$ 


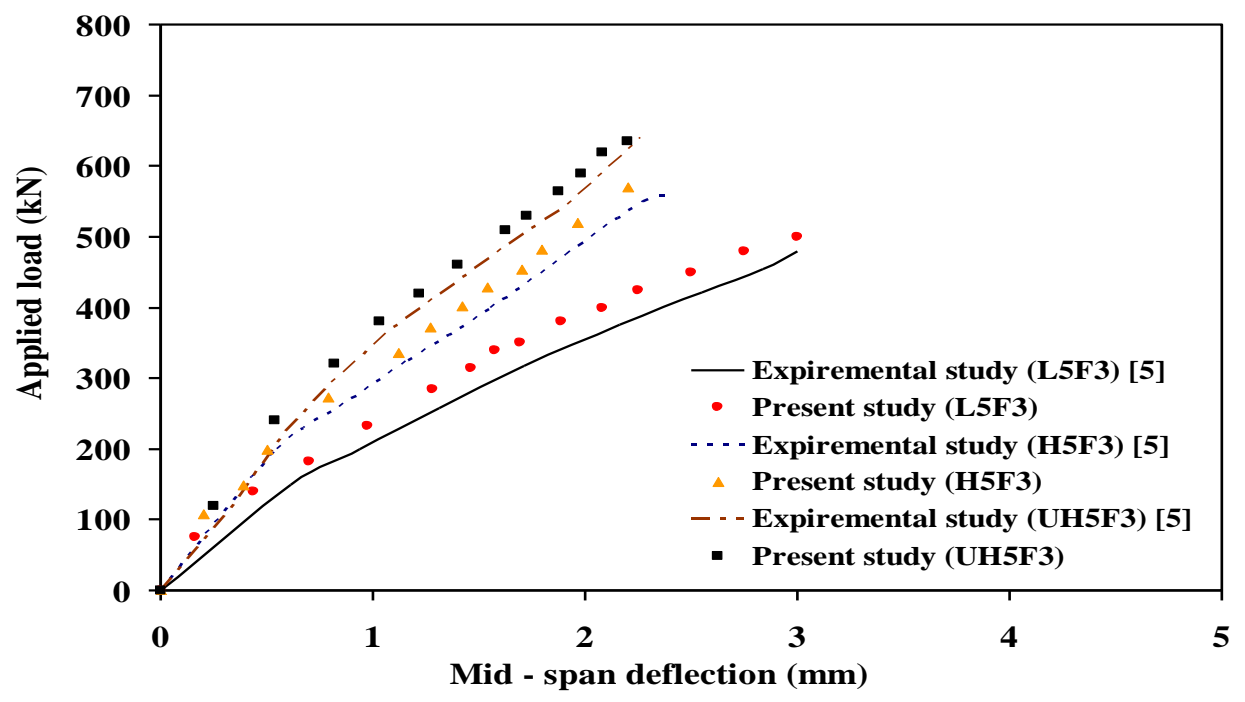

Figure (14): Load - deflection curve for (L5F3, H5F3 and $\mathrm{UHSF3})(\mathrm{a} / \mathrm{h}=\mathbf{0 . 5})$

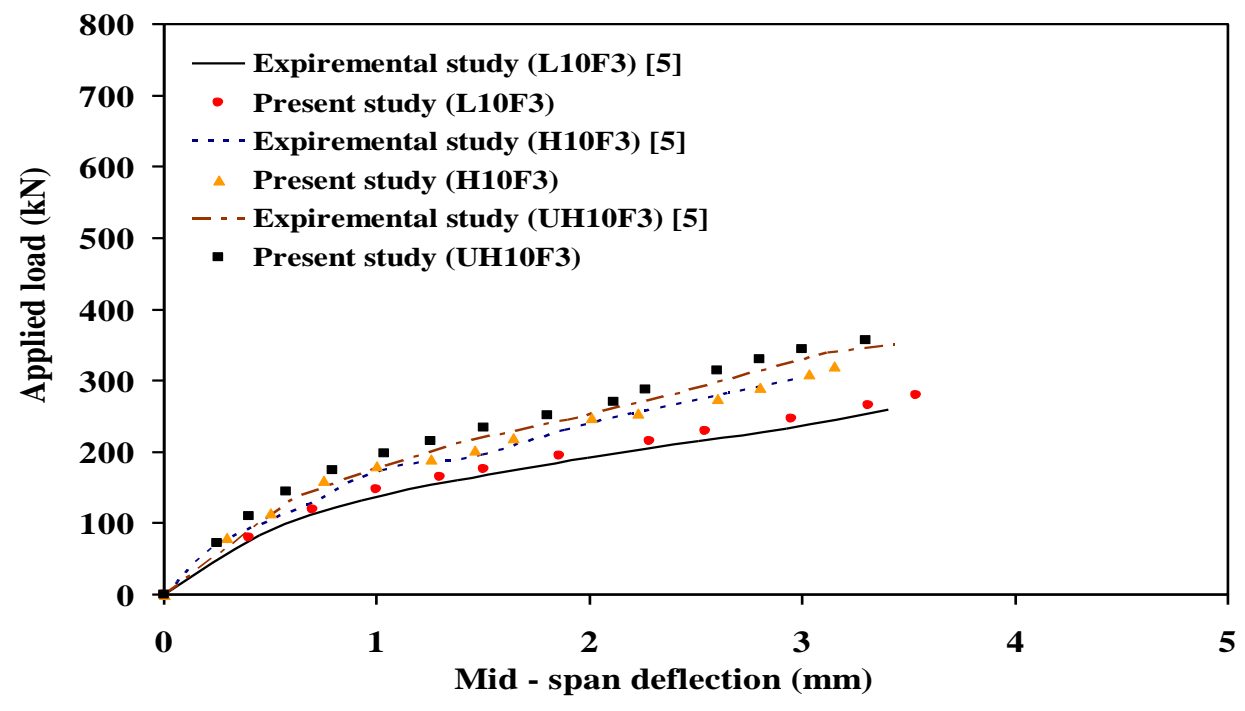

Figure (15): Load - deflection curve for $(\mathrm{L10NN}$, H10NN and UH10NN) $(\mathbf{a} / \mathrm{h}=\mathbf{1})$

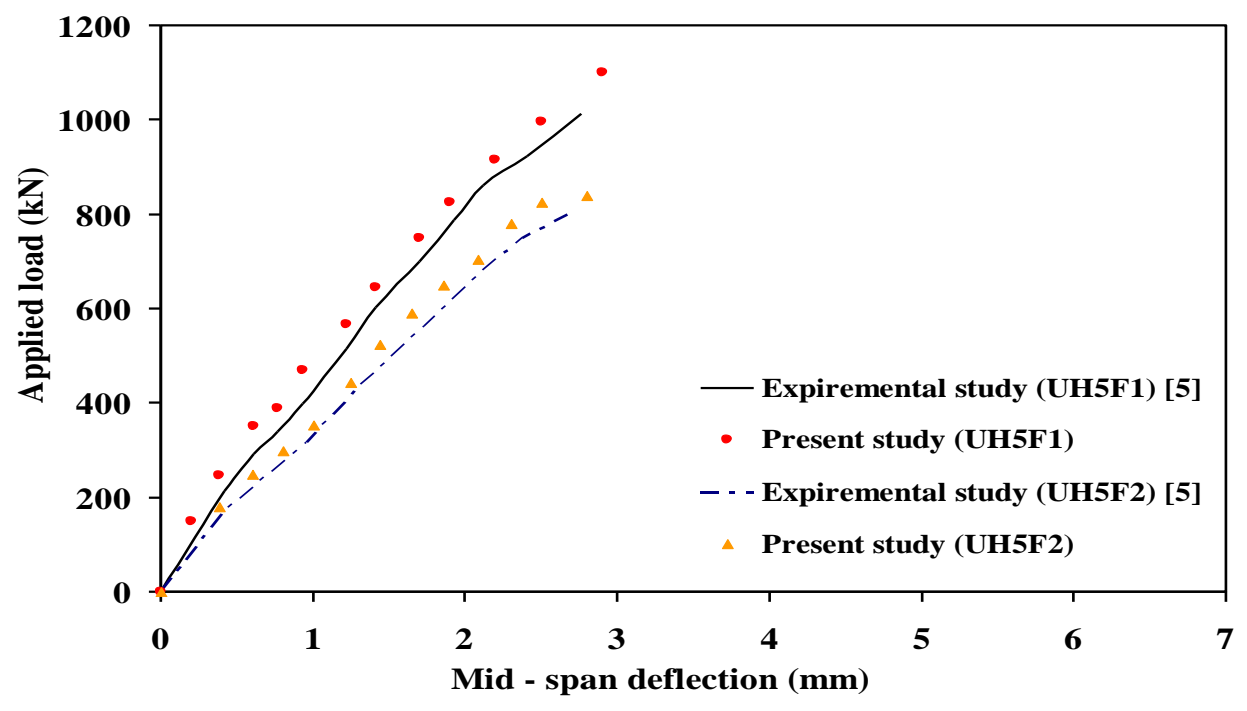

Figure (16): Load - deflection curve for (UH5F1, UH5F2)

$$
9^{(\mathbf{a} / \mathbf{h}=\mathbf{0 . 5})}
$$




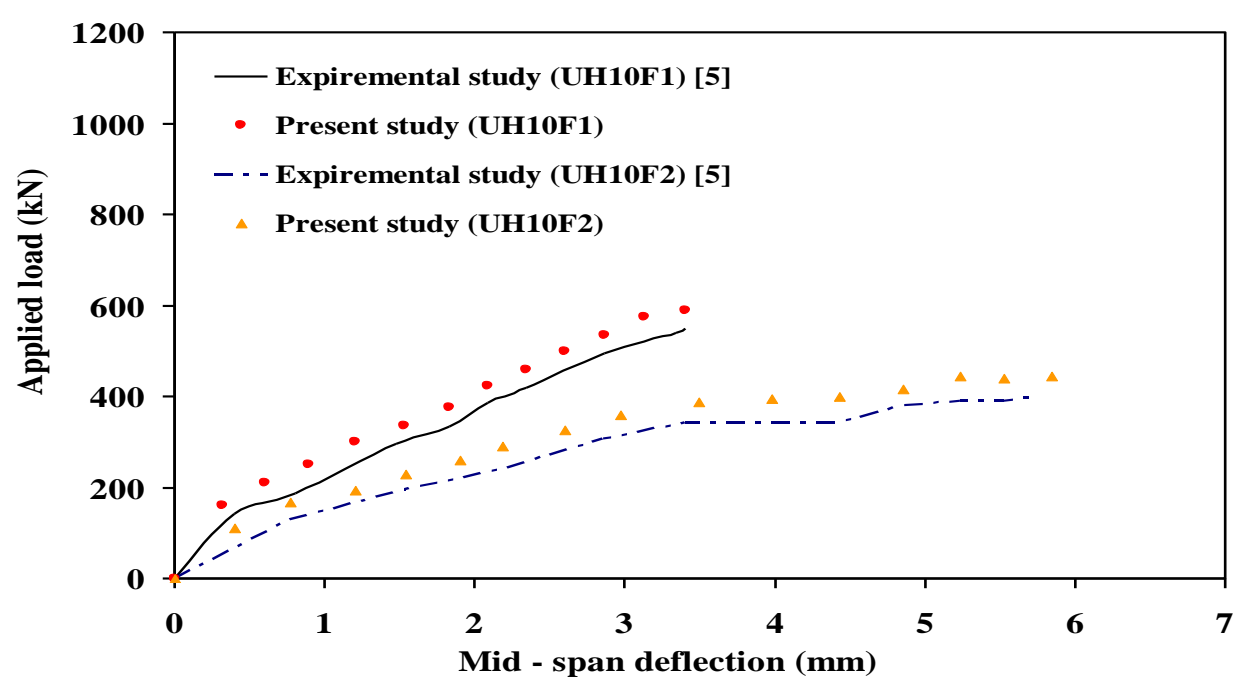

Figure (17): Load - deflection curve for (UH10F1, UH10F2) $(\mathbf{a} / \mathbf{h}=\mathbf{1 . 0})$

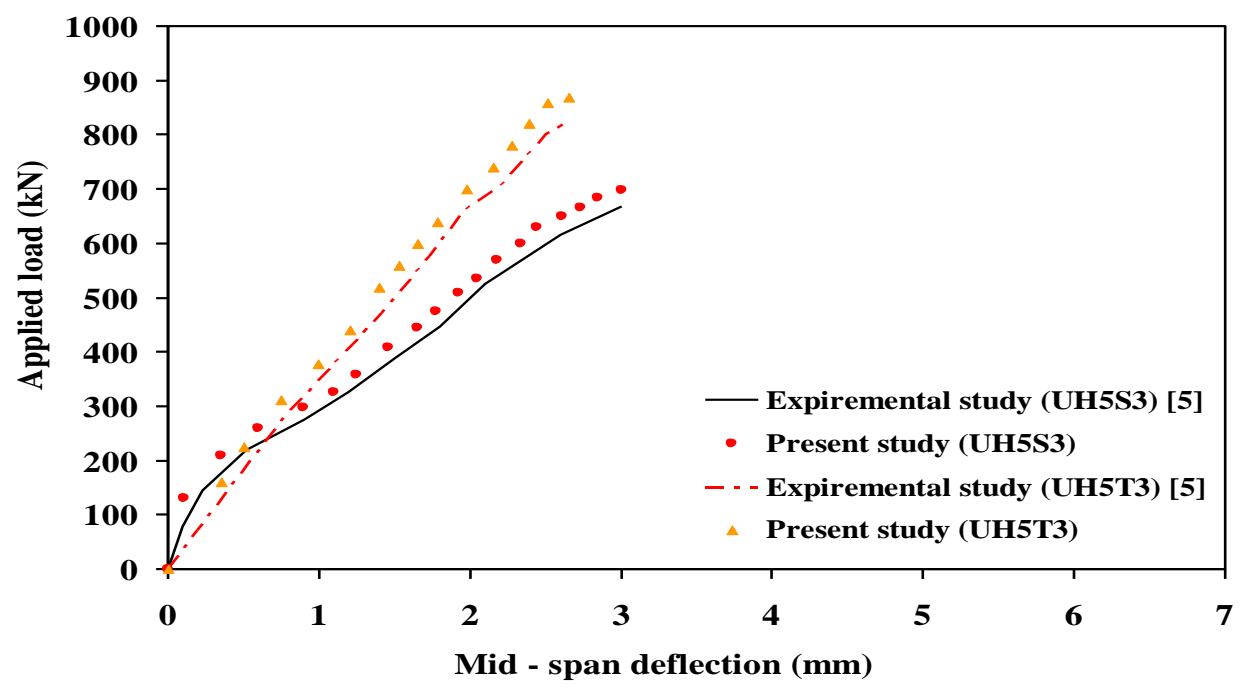

Figure (18): Load - deflection curve for (UH5S3, UH5T3) $(\mathrm{a} / \mathbf{h}=\mathbf{0 . 5})$

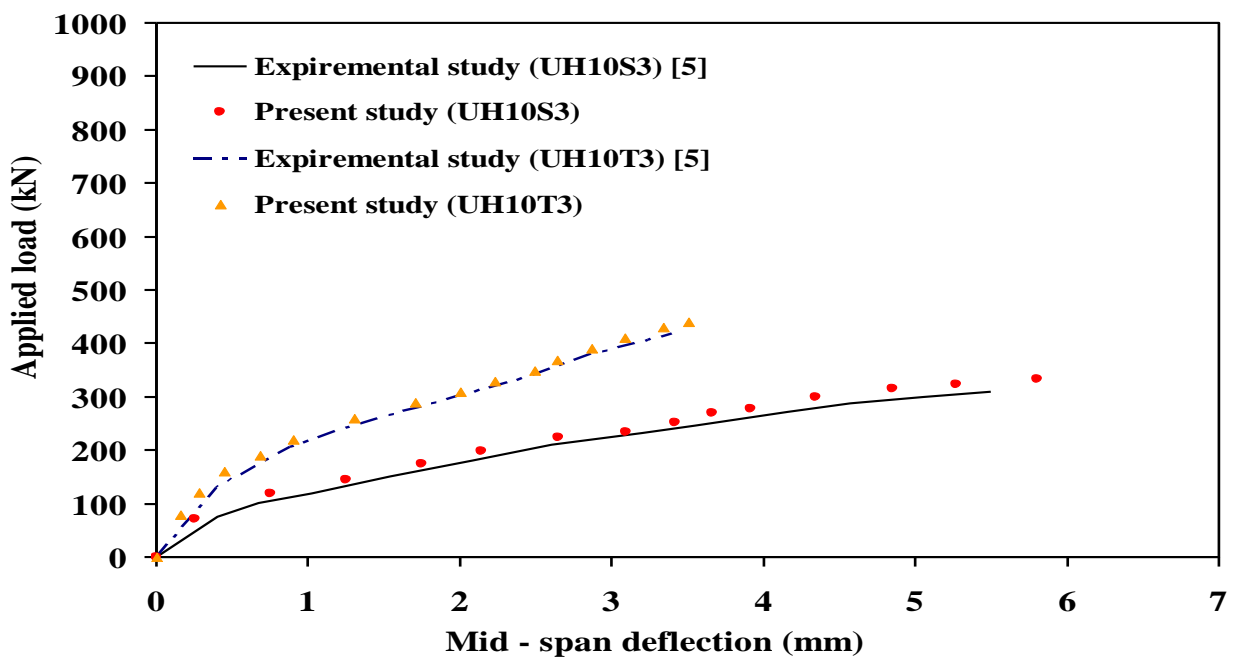

Figure (19): Load - deflection curve for (UH10S3, UH10T3)

$$
(\mathbf{a} / \mathbf{h}=\mathbf{1 . 0})
$$


From the figures shown above:

1. The deflection at mid span increased and the rigidity of the beams gradually decreased with an increase in shear - to - depth ratio.

2. The concrete strength affects the rigidity of beams and its effect on rigidity gradually increased as the shear span - to - depth ratio decreased.

3. The rigidity of beams with opening was rarely influenced by concrete strength due to decayed rigidity with an existence of the web openings.

The general failure modes of reinforced concrete members are represented by the occurrence and development of cracks. Figures (20 to 23) show the cracks development at failure for HSC (UH - series). It was found that the crack propagation, and failure plane depended on the size and location of the opening.

In solid beams, the first flexural cracks, generally appeared in the range of $(10 \%-$ $35 \%$ ) of maximum load, and these followed by independent diagonal cracks. The beam ultimately failed at concrete struts joining the load points and supports.

In deep beams with opening, the first diagonal cracks occurred near the bottom and top corners of openings (A and B are shown in Figure (10)). These cracks gradually developed towards the load points and supports, and there patterns depend on the opening size. Flexural cracks appeared in the range of $(50 \%-70 \%)$ of maximum load and developed towards corner $\mathrm{C}$ of the opening. With the increase in load, diagonal cracks newly formed near the corners $(\mathrm{C}$ or $\mathrm{D})$ of the openings towards supports and or load points.

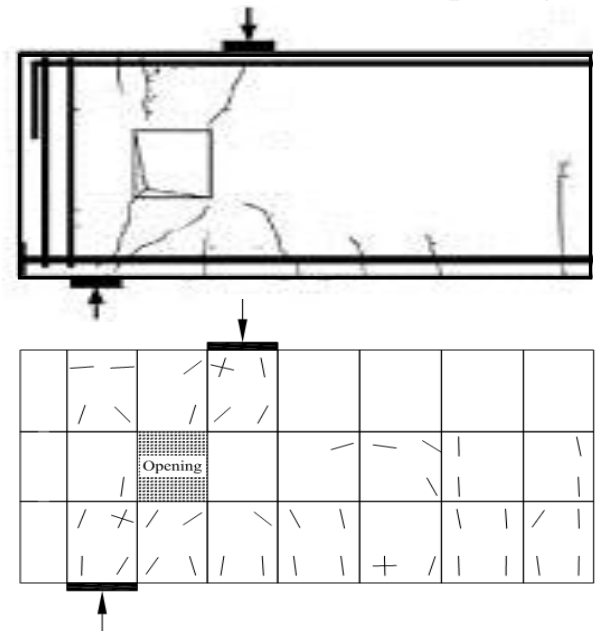

Figure (20): Crack pattern and failure for $(\mathrm{UH5F3}, \mathrm{a} / \mathrm{h}=\mathbf{0 . 5})[5]$

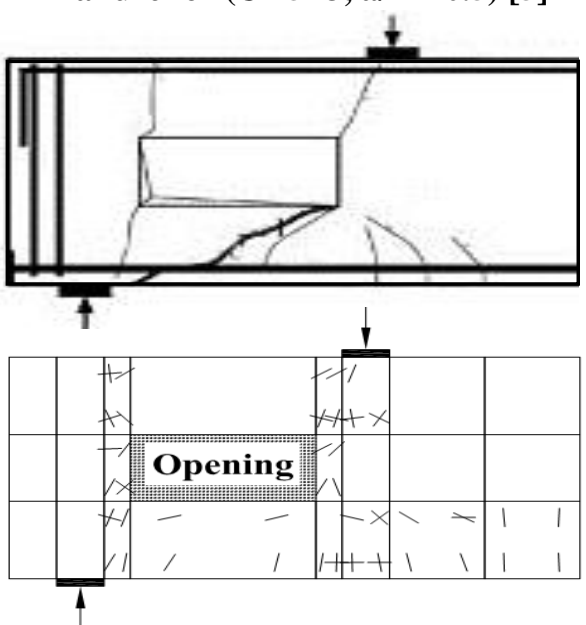

Figure (22): Crack pattern and failure for $(\mathrm{UH10S3}, \mathrm{a} / \mathrm{h}=1.0)[5]$

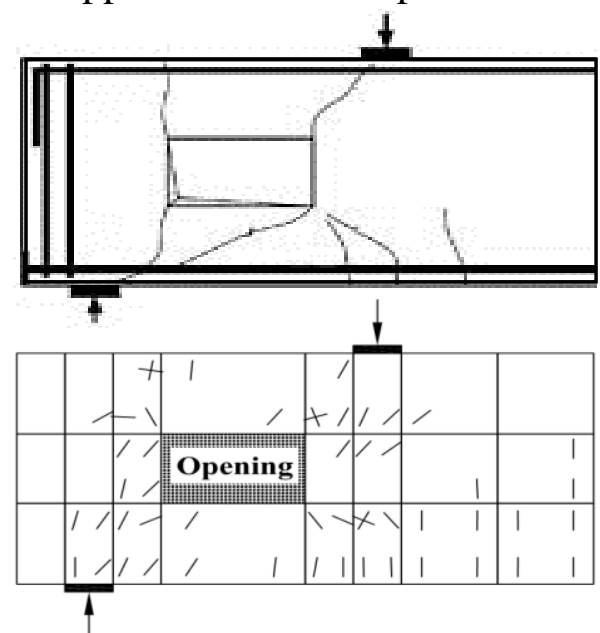

Figure (21): Crack pattern and failure for $(\mathrm{UH10F3}, \mathrm{a} / \mathrm{h}=1.0)$ [5]
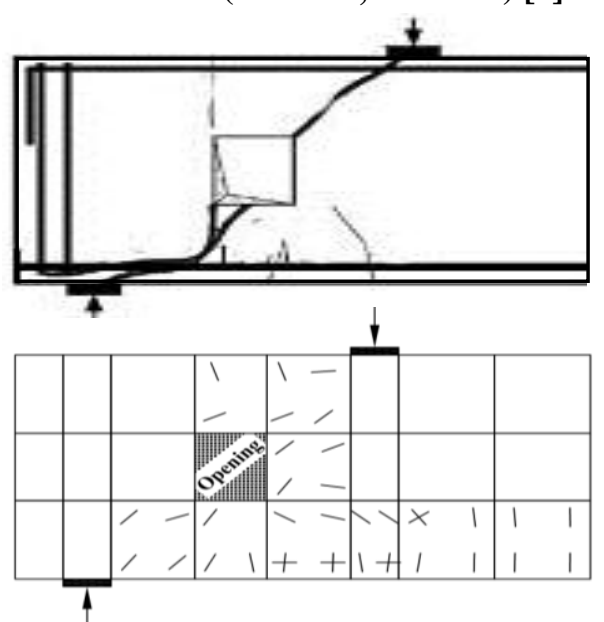

Figure (23): Crack pattern and failure for (UH10T3, a/h = 1.0) [5] 
Figures (24 and 25) show the longitudinal and shearing stresses at a load level of $550 \mathbf{~ k N}$ for deep beam (H5F3), it is can be seen from these figures that higher stresses occurred at the lower right corner of the opening and at load and support.

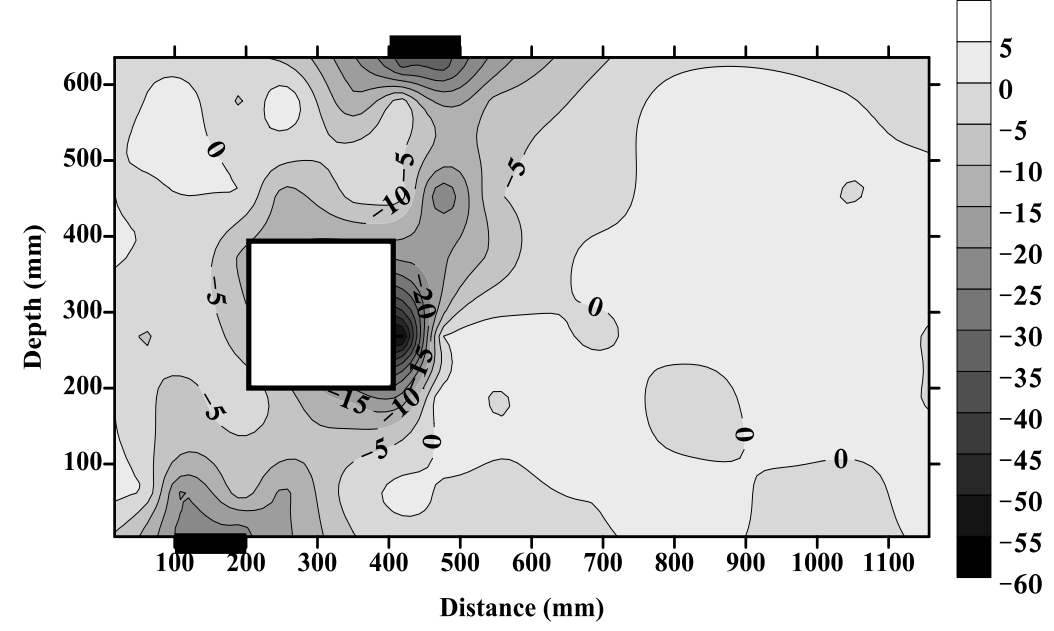

Figure (24): Longitudinal stress (MPa) at load level $550 \mathrm{kN}$ for beam H5F3 [5]

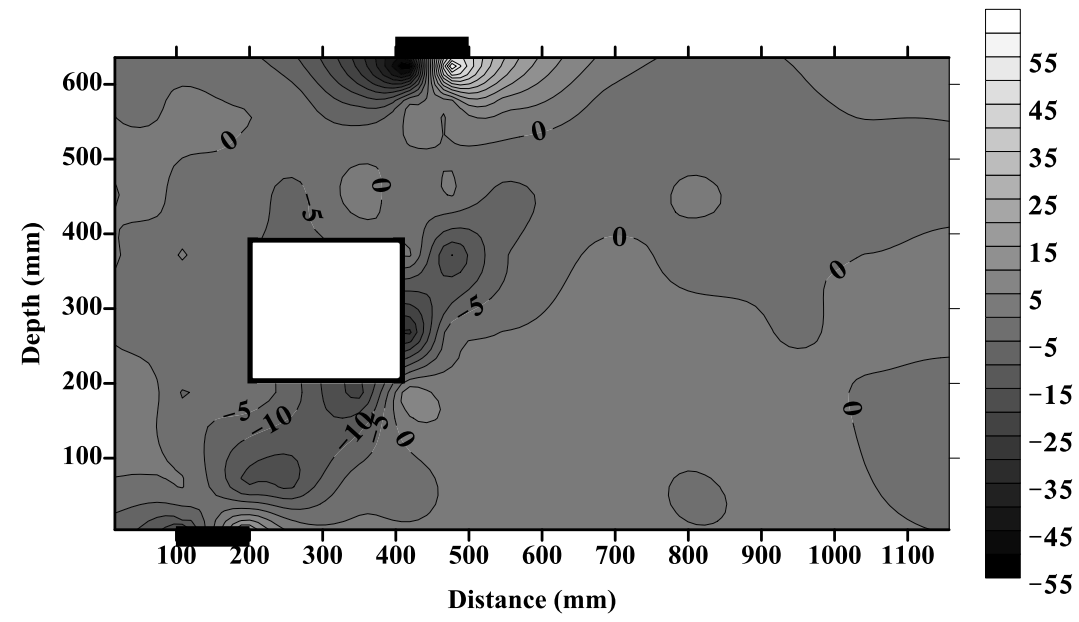

Figure (25): Shearing stress (MPa) at load level 550 kN for beam H5F3 [5]

When the width of opening increases with a constant depth, the failure load usually decreases, also when the depth increases with constant width the failure load usually decreases for span - to - depth ratio of $\mathbf{0 . 5}$ and $\mathbf{1 . 0}$ as shown in the Figure (26).

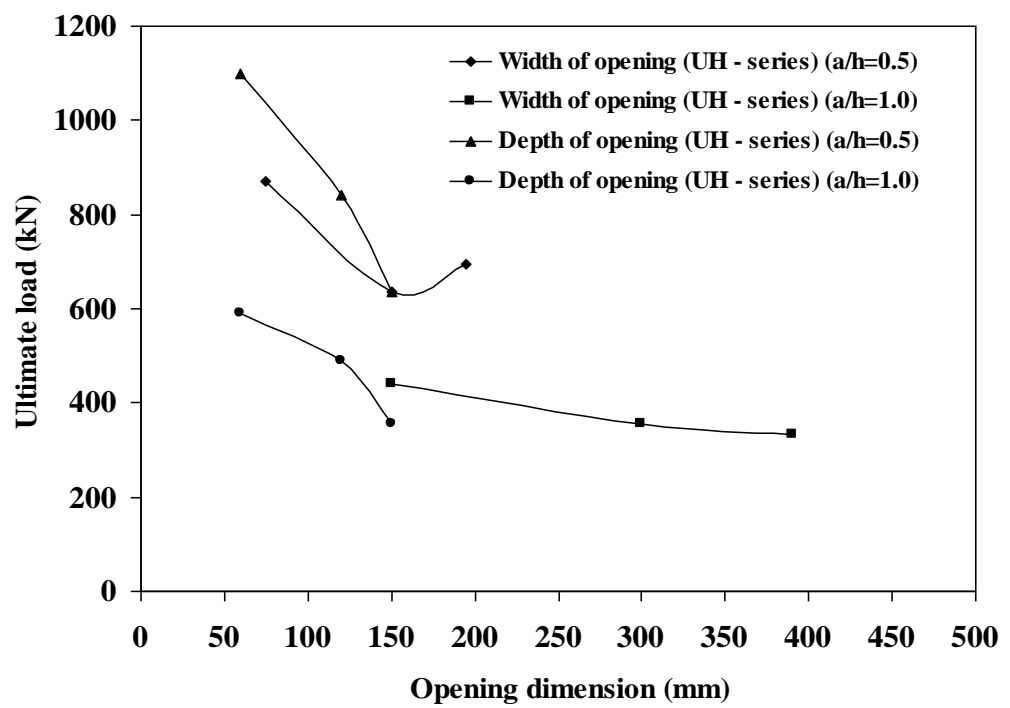

Figure (26): Effect of opening dimension on failure 
The increasing in the compressive strength of deep beam without opening has a significant effects on the ultimate load, while, in deep beam with opening the increasing in compressive strength has no significant effect as shown in Figure (27).

Table (3) shows the experimental and present study results, in terms of ultimate load with shear span - to - depth ratio of $\mathbf{0 . 5}$ and 1.0, a good agreement was noticed for beams specimens.

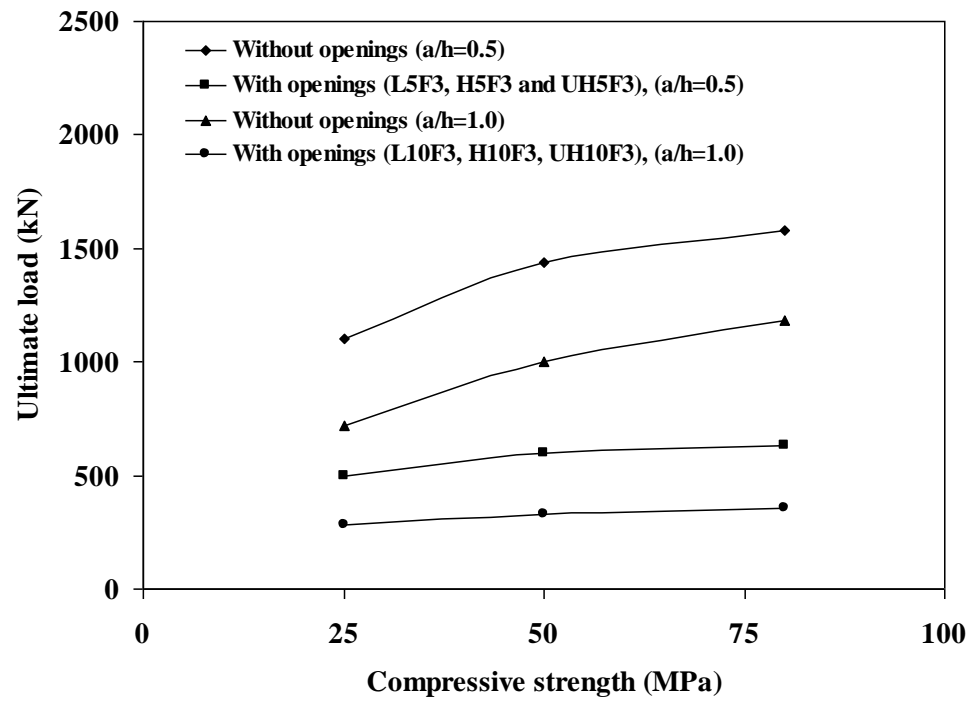

Figure (27): Effect of compressive strength on failure load (present study)

Table (3): Experimental and present study results for ultimate load

\begin{tabular}{|c|c|c|c|c|c|c|c|}
\hline \multirow[t]{2}{*}{ Specimen } & \multirow{2}{*}{$\begin{array}{c}\text { Concrete } \\
\text { strength } \\
\text { (MPa) }\end{array}$} & \multicolumn{3}{|c|}{$\mathrm{a} / \mathrm{h}=0.5$} & \multicolumn{3}{|c|}{$\mathbf{a} / \mathbf{h}=\mathbf{1 . 0}$} \\
\hline & & $\begin{array}{l}\text { Exp. } \\
\text { study } \\
(\mathrm{kN})\end{array}$ & $\begin{array}{c}\text { Present } \\
\text { study } \\
(\mathbf{k N})\end{array}$ & $\begin{array}{c}\text { Exp./ } \\
\text { Present }\end{array}$ & $\begin{array}{r}\text { Exp. } \\
\text { study } \\
(\mathbf{k N})\end{array}$ & $\begin{array}{c}\text { Present } \\
\text { study } \\
(\mathbf{k N})\end{array}$ & $\begin{array}{c}\text { Exp./ } \\
\text { Present }\end{array}$ \\
\hline L5NN & \multirow[t]{4}{*}{24} & 1100 & 1100 & 1.0 & & & \\
\hline L5F3 & & 500 & 480 & 1.041 & & & \\
\hline L10NN & & & & & 690 & 720 & 0.958 \\
\hline L10F3 & & & & & 250 & 280 & 0.892 \\
\hline H5NN & \multirow[t]{4}{*}{50} & 1400 & 1435 & 0.975 & & & \\
\hline H5F3 & & 560 & 600 & 0.933 & & & \\
\hline H10NN & & & & & 960 & 1003 & 0.957 \\
\hline H10F3 & & & & & 305 & 330 & 0.924 \\
\hline UH5NN & \multirow[t]{12}{*}{80} & 1600 & 1580 & 1.012 & & & \\
\hline UH5F1 & & 1000 & 1100 & 1.1 & & & \\
\hline UH5F2 & & 800 & 840 & 0.952 & & & \\
\hline UH5F3 & & 640 & 640 & 1 & & & \\
\hline UH5S3 & & 668 & 700 & 0.954 & & & \\
\hline UH5T3 & & 825 & 870 & 0.948 & & & \\
\hline UH10NN & & & & & 1100 & 1182 & 0.93 \\
\hline UH10F1 & & & & & 550 & 590 & 0.932 \\
\hline UH10F2 & & & & & 400 & 440 & 0.909 \\
\hline UH10F3 & & & & & 350 & 356 & 0.983 \\
\hline UH10S3 & & & & & 310 & 333 & 0.931 \\
\hline UH10T3 & & & & & 418 & 440 & 0.95 \\
\hline
\end{tabular}




\section{Conclusions}

This study investigated the effect of web openings through the numerical analysis to utilize concrete strength, shear span - to - depth ratio, and width and depth of opening.

The adopted solution algorithm and the derived material constitutive relationships gave a safe and realistic prediction of the behavior and strength of the investigated HSC deep beam with openings.

The deflection at mid - span increased and the rigidity gradually decreased when the span - to - depth ratio is increased. The width and depth of opening did not affect the mid span deflection at initial loading stages, but is significantly affected the deflection after the occurrence of diagonal crack.

The concrete strength did not largely affect the rigidity of beam with web opening due to existence of the web openings

The influence of concrete strength on the ultimate strength significantly decreased in deep beams with openings rather than solid deep beams.

The load carrying capacity of the HSC concrete deep beam with openings predicted by the finite element analysis gave a good agreement with the experimental study.

\section{References}

1. Dong Z, and Keru W, "Fracture properties of high strength concrete", Journal of Materials in Civil Engineering, Vol. 127, No. 1, January/ February, 2001, pp. 86 - 88.

2. Ho J.C.M., Lam J.Y.K, and Kwan A.K.H, "Effectiveness of adding confinement for ductility improvement of high strength concrete columns", Engineering Structures, Vol. 32, 2010, pp. $714-725$.

3. Masti K, Maghsoudi A.A, and Rahgozar R, "Nonlinear models and experimental investigation of lifetime history of HSC flexural beams", American Journal of Applied Sciences, Vol. 5, No. 3, 2008, pp. 248 - 262.

4. Yang K.Y, Chung H.S, Lee E.T, and Eun H.C, "Shear characteristics of high strength concrete deep beams without shear reinforcement", Engineering Structures, Vol. 25, 2003, pp. 1343 - 1352.

5. Yang K.H, Eun H.C, and Chung H.S, "The influence of web openings on the structural behavior of reinforced high strength concrete deep beams", Engineering Structures, Vol. 28, 2006, pp. 1825 - 1834.

6. Al - Ahmed A.H, "Finite element analysis of reinforced concrete corbels with steel fibers", M.Sc, Thesis, University of Technology, Iraq, March, 2006, 120pps.

7. Wee T.H, Chin M.S, and Mansur M.A, "Stress - strain relationship of high - strength concrete in compression", Journal of Materials in Civil Engineering, Vol. 8, No. 2, May, 1996, pp. $70-76$.

8. Oztekin E, Pul S, and Husem M, "Determination of rectangular stress block parameters for high performance concrete", Engineering Structures, Vol. 25, 2003, pp. $371-376$.

9. Ren X, Yang W, Zhou Y, and Li J, "Behavior of high performance concrete under uniaxial and bixial loading", ACI Material Journal, Vol. 105, No. 6, November December, 2008, pp. 548 - 557.

10. Marzouk H, and Chen Z.W, "Fracture energy and tension properties of high strength concrete", Journal of Materials in Civil Engineering, Vol. 7, No. 2, May, 1995, pp. $108-116$.

11. Abdul - Razzak A.A, "Non - Linear Finite Element Analysis of Fibrous Reinforced Concrete Structural Members", Ph.D, Thesis, University of Mosul, Iraq, August 1996. 237pps. 
12. Kuper H. B, Hilsdorf H. K, and Rusch $H$, "Behavior of concrete under biaxial stresses", ACI Journal Proceedings, Vol. 66, No. 8, August, 1996, pp. 656 - 666.

13. Lim D.H, and Nawy E.G, "Behavior of plain and steel - fiber - reinforced high strength concrete under uniaxial and biaxial compression", Magazine of Cement Research, Vol. 57, No. 10, 2005, pp. $603-610$.

14. Calixto J.M.F, "Microcracking of high performance concrete strength subjected biaxia tension - compression stresses", Materials Research, Vol. 5, No. 3, 2002, pp. $295-299$.

15. Hussein $\mathrm{A}$, and Marzouk $\mathrm{H}$, "Behavior of high - strength concrete under biaxial stresses", ACI Materials Journal, Vol. 97, No. 1, January - February, 2000, pp. 27 - 35.

16. Hampel T, Speck K, Scheerer S, Ritter R, and Curbach M, "High - performance concrete under biaxial and triaxial loads", Journal of Engineering Mechanics, ASCE, Vol. 135, No. 11, November, 2009, pp. $1274-1280$.

17. Cervenka V, "Constitutive model of cracked reinforced concrete", Vol. 82, No. 6, November - December, 1985, pp. 877 - 882.

18. Vecchio F.J, "Distributed stress filed model for reinforced concrete: formulation", Journal of Structural Engineering, Vol. 126, No. 9, September, 2000, pp. 1070 - 1077.

19. Hinton E. and Owen D.R.J, "Finite Element Programming", Academic Press Ltd., London 1977.

20. Hinton E and Owen D.R.J, "Finite Element Software for Plates and Shells", Pineridge Press, U.K, 1984.

The work was carried out at the college of Engineering. University of 